\title{
Relationships between a hermit crab and its shell resource: spatial patterns within a seagrass- dominated landscape
}

\author{
Bradley D. Robbins ${ }^{1, *}$, Susan S. Bell ${ }^{2}$ \\ ${ }^{1}$ Landscape Ecology Program, Mote Marine Laboratory, Sarasota, Florida 34236, USA \\ ${ }^{2}$ Department of Biology, University of South Florida, Tampa, Florida 33620, USA
}

\begin{abstract}
Abundance patterns of the hermit crab Pagurus maclaughlinae and its gastropod shell resources were compared to one another across the shallow subtidal landscape within Tampa Bay, Florida at a landscape (4.88 ha) and a sub-landscape $\left(1 \mathrm{~m}^{2}\right)$ scale. Specifically, we investigated whether the spatial abundance patterns of $P$. maclaughlinae over time could be explained by the abundance patterns of either future resources (i.e. live gastropods) or present resources (i.e. empty gastropod shells). The seagrass landscape was sampled for seagrass, hermit crabs, live gastropods and empty gastropod shells during the spring and fall of 1994 and 1995. The distribution of P. maclaughlinae could be explained by the distribution of its gastropod shell resources when the spatial organization of both $P$. maclaughlinae and these resources were compared across the landscape. Physical measures of the dominant seagrass Halodule wrightii (i.e. canopy height and shoot density) appeared to be unrelated to the distribution of $P$. maclaughlinae and either of its shell resources (present or future) across the landscape. These results suggest that hermit crabs track their 'limited' resources (i.e. gastropod shells) when viewed over the spatial scales examined here. Furthermore, our results suggest that the spatial distribution of future, as well as present resources, adds insight into patterns of hermit crab abundance.
\end{abstract}

KEY WORDS: Hermit crab · Gastropod · Resources · Abundance pattern · Spatial analysis · Seagrass · Landscape $\cdot$ Pagurus maclaughlinae $\cdot$ Halodule wrightii

\section{INTRODUCTION}

Within marine environments, landscape heterogeneity may play a role in shaping the interactions between 2 species by affecting their abundance and/or distribution patterns (Danielson 1991). Quantifying the spatial nature of these distributional relationships and recognizing the patterns they generate are fundamental to understanding an organism's ecology. However, direct and indirect interactions between an organism, its resources and the environment may cause difficulty in elucidating mechanisms underlying spatial relationships. For example, associations between abundances of epifauna and the presence/absence of seagrass documented in the marine literature (e.g. Heck \& Wet- stone 1977, Orth et al. 1984, Bell \& Pollard 1989) may be explained by the spatial abundance of faunal prey, which can also associate with seagrass, rather than by a direct association between seagrass and epifauna (Connolly 1994). Thus, quantifying the spatial distribution of an organism and its resources within a landscape may provide information on what controls distribution patterns that might not be obvious from information collected without reference to spatial position.

Delineation of the spatial relationships of a target organism and its resource(s) requires a detailed, often unavailable, knowledge of resource utilization patterns. An examination of the spatial patterns formed by a hermit crab and its shell resources provides an 
excellent model by which to test ideas about habitat heterogeneity, faunal abundance, resource availability and their respective linkages to vegetation. This follows from the well-discussed paradigm that empty gastropod shells are a limiting resource for (at least) the larger size classes of hermit crabs (e.g. Provenzano 1960, Hazlett 1970, 1981, Kellogg 1976, Spight 1977, Scully 1979, Abrams 1980, Lancaster 1990). If gastropod shells are indeed limiting, then one might predict that the distribution of hermit crabs should be tightly linked to the distribution of empty gastropod shells. Moreover, these distribution patterns may have a strong spatial component that is related to landscape characteristics (e.g. vegetation characteristics or habitat heterogeneity) because of the habitat affinity displayed by both the hermit crab and the gastropod species that are providing shells (Robbins 1998).

A caveat to the paradigm of the hermit crab shell association exists, however, with regard to the definition of gastropod shell 'availability.' Typically, available gastropod shells have been defined as 'empty,' but gastropod shells occupied by hermit crabs (Walters \& Griffiths 1987, Robbins 1998) and live gastropods (McLean 1983) may also be 'available.' The distinction then is the asynchronous accessibility of these resources; some portion of the resource is immediately available (empty shells), while other portions are likely to become available at a future time (living gastropods and shells occupied by other hermit crabs). Thus, all gastropod shells are potential resources for hermit crabs until they are either physically removed from the system or rendered unusable by damage (e.g. through predation).

If a relationship exists between the spatial abundance patterns of hermit crabs and empty gastropod shells, then one might hypothesize that hermit crabs track their future resource (i.e. live gastropods) as well as their immediate resource (i.e. empty gastropod shells), especially if the availability of empty shells is transitory. Thus, one might predict that hermit crab distribution patterns reflect the distribution patterns of both their immediate and future resources. Additionally, the abundance patterns displayed by an organism or its resources may also reflect habitat features such as seagrass density (sensu Irlandi et al. 1994). Both hermit crabs and live gastropods may actively choose to associate with vegetation features, whereas any association between dead shells and seagrass is dependent on either the shell's previous occupant's behavior and/or the passive movement of shells after their abandonment by an occupant. Therefore, a discussion of the association between a hermit crab and its gastropod shell resources without consideration of underlying habitat characteristics may be incomplete.
Our primary objective in this study was to evaluate the spatial relationships between a resource user and the availability of its limiting resource in a marine landscape. We investigated the relationship between Pagurus maclaughlinae and its gastropod shell resources with respect to physical measures of seagrass (shoot density and canopy height) within the landscape. More specifically, we asked (1) are the distribution patterns of $P$. maclaughlinae and its present and future resources explained by seagrass physical characteristics and (2) is there a temporally consistent spatial relationship between $P$. maclaughlinae and its present and future gastropod shell resources?

\section{MATERIALS AND METHODS}

Study site. The study site was a $122 \times 400 \mathrm{~m}$ landscape located on a shallow subtidal shoal immediately adjacent to Mullet Key, Tampa Bay, Florida $\left(27^{\circ} 45^{\prime} \mathrm{N}\right.$, $83^{\circ} 38^{\prime} \mathrm{W}$ ). Both monospecific and mixed stands of seagrass were found covering approximately $50 \%$ of the landscape with Halodule wrightii (shoal grass) as the dominant seagrass $(\sim 74 \%$ of all seagrass). Detailed maps (1 m resolution) of seagrass areal extent were obtained during the spring and fall of 1994 (S94 and F94) and 1995 (S95 and F95). A full description of the study site and the mapping technique used can be found in Robbins \& Bell (2000).

Two hermit crab species, Pagurus maclaughlinae and $P$. longicarpus, were commonly found at this site, with $P$. maclaughlinae numerically dominant $(\geq 95 \%$ of all hermits collected; Robbins 1998). Shells of 6 gastropod species (Anachis translirata Rav., Cerithium muscarum Say, Modulus modulus Linn., Nassarius vibex Say, Olivella mutica Say, and Prunum apicinum Menke) were regularly used by $P$. maclaughlinae and were the targets of this study. A detailed description of shell use patterns and life history characteristics of the hermit crabs and gastropods at this study site can be found in Robbins (1998).

Sampling. On each mapping date, 63 haphazardly selected $1 \mathrm{~m}^{2}$ areas within monospecific Halodule wrightii patches were georeferenced and sampled by removing a $15.25 \mathrm{~cm}$ diameter core taken to a depth of $30 \mathrm{~cm}$ into the substratum. Seagrass samples were rinsed in the field to remove sediments and brought to the laboratory within individual Ziploc ${ }^{\circledR}$ bags. After separating seagrass into above and below-ground components, short-shoot density was enumerated and mean maximum canopy height $( \pm 1 \mathrm{~mm})$ was determined by measuring the longest blade from 10 haphazardly selected shoots. These seagrass descriptors were chosen to represent the horizontal and vertical structure of seagrass within the landscape. 
Hermit crabs, living gastropods and empty gastropod shells were collected using a $1 \mathrm{~m}^{2}$ throw trap placed immediately adjacent to the georeferenced seagrass core sites. Throw traps were constructed using a $10 \mathrm{~cm}$ tall, $16 \mathrm{~g}$ metal flange and a $5 \mathrm{~cm}$ diameter PVC float attached to $2 \mathrm{~mm}$ mesh, $1 \mathrm{~m}$ in height. Sampling was conducted at mid-day during slack low tide by repeatedly passing a dip net $(0.5 \times 0.5 \mathrm{~m}$ with $2 \mathrm{~mm}$ mesh) through the trap, taking care to disturb the sediment surface and the seagrass canopy, until no further hermit crabs or gastropod shells were collected. Collected hermit crabs, living gastropods and empty shells were preserved in $70 \%$ ethanol, and returned to the laboratory. Samples were then enumerated and shell species and occupant (living, empty or hermit crab by species) were recorded.

Data analysis. Seasonal (S94 to F94, F94 to S95 and S95 to F95) differences in seagrass physical characteristics and the densities of gastropod shell occupants per $\mathrm{m}^{2}$ (as defined above) were examined using a Kruskal-Wallis ANOVA (Zar 1996) with each sampling site used as a replicate ( $\mathrm{n}=63$ per season). Only Pagurus maclaughlinae and the gastropod shells commonly used (see Tunberg et al. 1994, Robbins 1998) by this hermit crab (and of an appropriate size) were considered for analysis. To isolate seasons in which habitat features and gastropod shell abundances differed, we used a pairwise multiple comparisons technique (Dunn's Method: Howell 1987). The relationships among abundances of different shell occupants by date were examined using Spearman Rank Correlation (Zar 1996). No species level analyses were performed.

Because we were interested in the spatial association among hermit crabs, live gastropods and empty shells, we used a residual analysis to examine whether high densities of Pagurus maclaughlinae (represented as densities $\geq 1$ SD above the mean) corresponded to high or low densities (ranging from $-1 \mathrm{SD}$ to $+2 \mathrm{SD}$ above the mean) of live gastropods and empty shells. To accomplish this, we assigned each of the 63 sampling locations, based on raw values, to 1 of 5 categories for each of the shell occupants and the seagrass descriptors: mean, $\pm 1 \mathrm{SD}$ or $+2 \mathrm{SD}$. These data were then interpolated using an inverse distance weighted interpolation technique (Koerper 1993). For each date, abundance maps based on P. maclaughlinae, live gastropod, empty shell, seagrass shoot density and canopy height categories were generated using GRASS (Geographic Resources Analysis Support System 4.1; maps are available in Robbins 1998). Cross-correlation analysis was used to examine the spatial arrangement of our variables (hermit crabs, gastropods, empty shells and seagrass descriptors) by examining the spatial variation of variable densities and their associated relationships. Because these comparisons were based on interpolated data, no statistical significance can be attached to any observed correlations (Davis 1986).

\section{RESULTS}

Physical attributes of Halodule wrightii among sites varied seasonally; abundance measured as short-shoot density, was found to be significantly different between spring and fall ( $\mathrm{p} \leq$ 0.001) for both 1994 and 1995 (Fig. 1a). No differences were detected in the abundance of seagrass from the same seasons, however ( $p \geq 0.05$ ). Canopy height during F95 was significantly greater than in S94 or S95 ( $p \leq 0.001$ ), while all other pairwise comparisons were not significantly different ( $\mathrm{p} \geq 0.05$ ) (Fig. 1b).

A significant difference was observed in the number of Pagurus maclaughlinae collected per $\mathrm{m}^{2}$ over seasons ( $p=0.011$, Fig. 2) although the only significant pairwise difference occurred between the S95 and F95 comparison. A significant difference was also found in the number of gastropods $\mathrm{m}^{-2}$ among seasons $(\mathrm{p} \leq$ 0.001 ) with significantly more gastropods found during S95 than in all other seasons ( $p \leq 0.05$, Fig. 2). Few

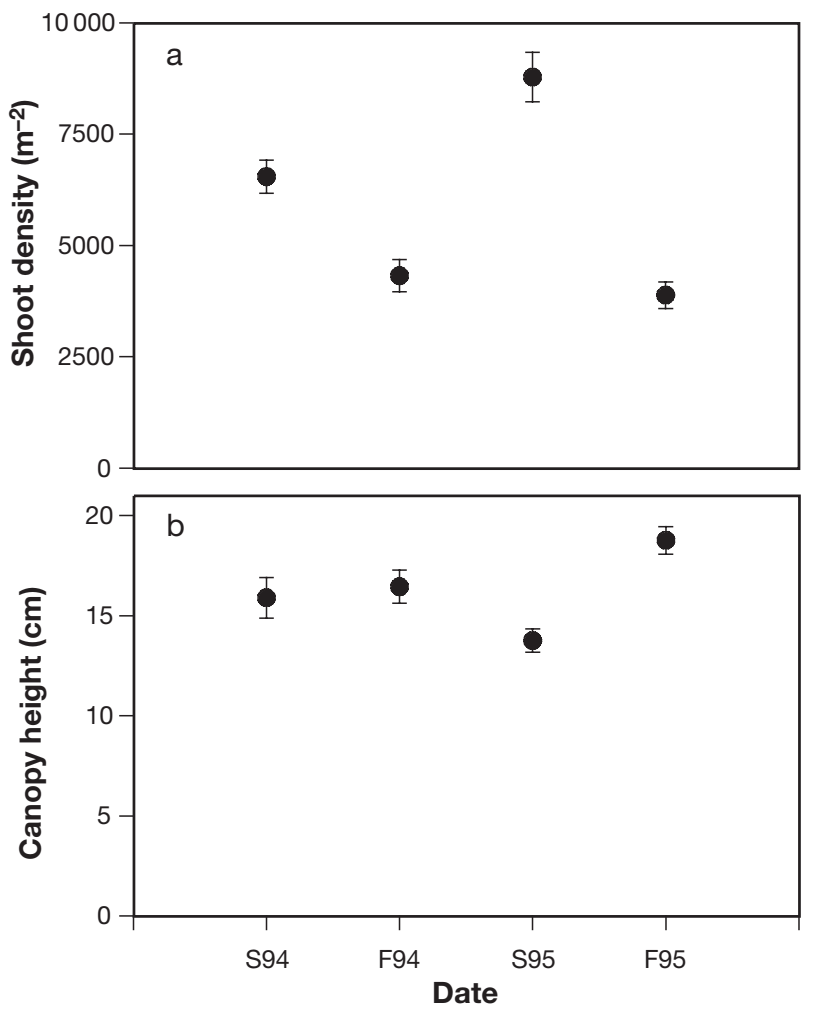

Fig. 1. Halodule wrightii. Seasonal differences in (a) the mean abundance in short-shoots $( \pm \mathrm{SE})$ and $(\mathrm{b})$ canopy height $( \pm \mathrm{SE})$ as measured by mean maximum blade length $(\mathrm{cm})$. S94, F94 and S95, F95: spring and fall of 1994 and 1995, respectively 


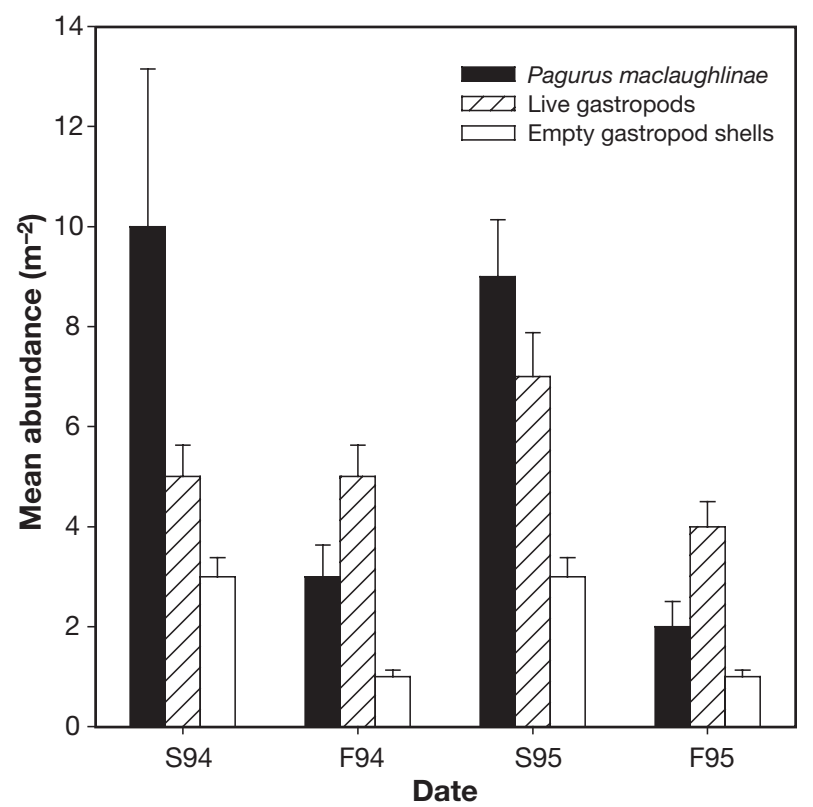

Fig. 2. Pagurus maclaughlinae. Seasonal differences among mean abundances $(+\mathrm{SE})$, live gastropods and empty gastropod shells over the sampled seasons

empty shells were collected in F94 and F95. There were significantly fewer shells present during the F94 season than S94 ( $\mathrm{p} \leq 0.001$, Fig. 2), but the same seasonal comparison in 1995 proved non-significant $(\mathrm{p} \geq$ 0.05, Fig. 2).

A positive and statistically significant correlation was found between the numbers of Pagurus maclaughlinae and live gastropods for each of the 4 seasons sampled (Table 1). Dates within 1995 displayed a weaker correlation between hermit crabs and live gastropods than 1994. Although 3 of the 4 seasonal correlations between empty shells and $P$. maclaughlinae were significant, only 1 (S94) showed a strong correlation (Table 1).

A pairwise comparison of seagrass descriptors and shell occupants found only a single significant relationship (empty shell versus canopy height during S95; Table 2). The nature of all relationships between live gastropods and hermit crabs versus canopy height were most often negative, while for shoot density, they were typically positive. In general, at the scale of our sampling, there was little indication of any consistent relationship between shell occupants and vegetation characteristics.
Cross-correlation analyses conducted to examine the spatial relationship among Pagurus maclaughlinae, gastropods and empty shells revealed that the number of $P$. maclaughlinae $\mathrm{m}^{-2}$ was strongly correlated with the number $\mathrm{m}^{-2}$ of both live gastropods and empty gastropod shells across all seasons (Table 3 ). The relationships between $P$. maclaughlinae and empty gastropod shells were typically positive and stronger than those between $P$. maclaughlinae and live gastropods, except for F94. Overall, the relationship between empty gastropod shells and gastropods was stronger during F94 and F95, when both hermit crab densities and empty

Table 1. Correlation coefficients (r) and significance values (p) based on Spearman Rank correlations among Pagurus maclaughlinae (hermit), live gastropods (live) and empty gastropod shells (empty) numbers $\mathrm{m}^{-2}$ by date (S94, F94 and S95, F95: spring and fall of 1994 and 1995, respectively)

\begin{tabular}{|llcccc|}
\hline & & \multicolumn{2}{c}{ Hermit } & \multicolumn{2}{c|}{ Empty } \\
& & $\mathrm{r}$ & $\mathrm{p}$ & $\mathrm{r}$ & $\mathrm{p}$ \\
\hline S94 & Live & 0.84 & 0.0001 & 0.60 & 0.0001 \\
& Empty & 0.80 & 0.0001 & - & - \\
F94 & Live & 0.91 & 0.0001 & 0.40 & 0.002 \\
& Empty & 0.38 & 0.003 & - & - \\
S95 & Live & 0.58 & 0.0001 & 0.47 & $\mathrm{a}$ \\
& Empty & 0.39 & 0.002 & - & - \\
F95 & Live & 0.23 & 0.022 & 0.39 & 0.002 \\
& Empty & 0.22 & 0.081 & - & - \\
a A test of significance was not possible between live gas- \\
tropods and empty shells, because relatively few empty \\
shells were found compared to live gastropods during \\
this season (S95)
\end{tabular}

Table 2. Relationships among shell category occupants (Pagurus maclaughlinae, live gastropods and empty shells) and the physical characteristics measured for Halodule wrightii (mean short-shoot density and canopy height) ( $\mathrm{n}=63$ per date). Spearman Rank Correlation values are reported with p-values listed immediately below. Shoots $=$ shoot density $\mathrm{m}^{-2} ;$ Canopy $=$ mean maximum blade length $(\mathrm{cm}) ;$ Hermit $=$ Pagurus maclaughlinae $;$ Live $=$ gastropods $;$ Empty $=$ empty shells

\begin{tabular}{|llrrrrrrc|}
\hline & & \multicolumn{2}{c}{ Hermit } & \multicolumn{2}{c}{ Live } & \multicolumn{2}{c|}{ Empty } \\
& & $\mathrm{r}$ & $\mathrm{p}$ & $\mathrm{r}$ & $\mathrm{p}$ & $\mathrm{r}$ & $\mathrm{p}$ \\
\hline S94 & Shoots & 0.04 & 0.73 & 0.09 & 0.47 & 0.01 & 0.96 \\
& Canopy & -0.05 & 0.67 & -0.08 & 0.51 & 0.01 & 0.94 \\
F94 & Shoots & 0.21 & 0.14 & 0.12 & 0.38 & 0.22 & 0.11 \\
& Canopy & -0.11 & 0.41 & -0.11 & 0.41 & 0.001 & 0.99 \\
S95 & Shoots & -0.07 & 0.61 & 0.02 & 0.86 & 0.20 & 0.12 \\
& Canopy & -0.21 & 0.18 & 0.12 & 0.45 & -0.30 & 0.05 \\
F95 & Shoots & -0.11 & 0.37 & 0.18 & 0.15 & 0.24 & 0.06 \\
& Canopy & -0.06 & 0.63 & -0.05 & 0.72 & 0.002 & 0.99 \\
\hline
\end{tabular}


Table 3. Cross-correlation matrix by season, for relationships among shell category occupants (Pagurus maclaughlinae, live gastropods and empty shells). Unlike simple correlations that may be influenced by a large deviation within a small region of the sampled area, this matrix reflects the spatial arrangement of the relationships among the variables. Values are $\mathrm{r}^{2}$ correlations for each pairwise comparison. Because correlations are based on interpolated values, no statistical significance can be attached

\begin{tabular}{|clccrc|}
\hline & & Gastropod & Empty & Shoot & Canopy \\
\hline S94 & Hermit & 0.69 & 0.77 & -0.20 & -0.20 \\
& Gastropod & & 0.49 & 0.03 & -0.20 \\
& Empty & & & -0.22 & -0.23 \\
& Shoots & & & & -0.13 \\
F94 & Hermit & 0.79 & 0.79 & 0.43 & 0.55 \\
& Gastropod & & 0.87 & 0.56 & 0.41 \\
& Empty & & & 0.67 & 0.58 \\
& Shoots & & & & 0.38 \\
S95 & Hermit & 0.56 & 0.85 & 0.73 & 0.63 \\
& Gastropod & & 0.50 & 0.66 & 0.31 \\
& Empty & & & 0.65 & 0.59 \\
& Shoots & & & & 0.59 \\
F95 & Hermit & 0.77 & 0.83 & 0.64 & 0.53 \\
& Gastropod & & 0.73 & 0.62 & 0.40 \\
& Empty & & & 0.47 & 0.51 \\
& Shoots & & & & 0.66 \\
\hline
\end{tabular}

shells were at lower densities than those recorded in either S94 or S95 (Table 3).

Information gleaned from the abundance categories provided additional insight into the nature of the associations between hermit crabs and their shell resources. Specifically, high densities of hermit crabs were much less likely to occur within areas where the densities of gastropods and/or empty shells were equal to or lower than their mean value (Table 4). Comparison of spatial distributions represented by mean densities revealed that, overall, at more than $50 \%$ of locations with Pagurus maclaughlinae densities 1 SD above their mean co-occurred with areas where live gastropod densities were greater than their own mean (Total\% $\geq 1$ SD line; Table 4). Comparatively, 75\% of $P$. maclaughlinae aggregations with densities $2 \mathrm{SD}$ above the mean were in areas where live gastropod densities were greater than their own mean (Total\% > 1 SD line; Table 4). Thus, the majority of locations with highest densities of hermit crabs corresponded to locations with the densest aggregations of live gastropods. The relationship between hermit crab and empty shells was less strong (Table 4). Notably hermit crabs at densities $2 \mathrm{SD}$ above their mean were never found in areas with gastropod densities $1 \mathrm{SD}$ below their mean and only during S94 were these hermit crab aggregations recorded associated with empty shell aggregations $1 \mathrm{SD}$ below their mean.

\section{DISCUSSION}

Seagrass descriptors did not appear to explain the patterns of abundance of hermit crabs or their resources over the duration of our study. Specifically, our results indicate that neither mean short-shoot density nor mean maximum canopy height were strong predictors of abundance patterns of hermit crabs when compared over this scale. There were also no consistent relationships between seagrass and categories of shell occupants detected at the small spatial scale. These responses are aligned with previous findings that the distribution and abundance of many fish and decapod species are not controlled by the physical complexity of the seagrass landscape (e.g. Bell et al. 1988, Hovel \& Lipcius 2002), nor does the variation in seagrass shoot density within a patch explain large scale variation in the abundance of associated fishes or decapods (Worthington et al. 1992, Hovel \& Lipcius 2002, see also Attrill et al. 2000).

Hermit crab abundance displayed associations with shell resources. Overall, the correlative information and the data gathered from examining spatial patterns of abundance indicated a positive and significant relationship between hermit crabs and live shells that persisted over time. The relationship between hermit

Table 4. Pagurus maclaughlinae. Relationship between aggregations of hermit crabs and aggregations of live gastropods, and empty shells as represented by the percentage of the landscape with hermit crab densities $1 \mathrm{SD}$ and $2 \mathrm{SD}$ above the mean density located in areas of differing densities of live and empty gastropod shells. For example, in S94 50\% of locations where hermit crab densities were 1 SD above their mean also had gastropod densities $2 \mathrm{SD}$ above their means

\begin{tabular}{|c|c|c|c|c|c|c|}
\hline & & $-1 \mathrm{SD}$ & Mean & $+1 \mathrm{SD}$ & $+2 \mathrm{SD}$ & Total $>$ Mean \\
\hline \multicolumn{7}{|c|}{$1 \mathrm{SD}$ above mean } \\
\hline \multirow[t]{2}{*}{ S94 } & Live & 18 & 24 & 8 & 50 & 58 \\
\hline & Empty & 18 & 14 & 65 & 3 & 68 \\
\hline \multirow{2}{*}{ F94 } & Live & 21 & 21 & 4 & 53 & 57 \\
\hline & Empty & 0 & 0 & 1 & 0 & 1 \\
\hline \multirow[t]{2}{*}{ S95 } & Live & 21 & 26 & 36 & 18 & 54 \\
\hline & Empty & 12 & 35 & 48 & 5 & 53 \\
\hline \multirow[t]{2}{*}{ F95 } & Live & 33 & 10 & 23 & 33 & 56 \\
\hline & Empty & 17 & 52 & 31 & 1 & 32 \\
\hline \multicolumn{7}{|c|}{2 SD above mean } \\
\hline \multirow[t]{2}{*}{ S94 } & Live & 0 & 16 & 41 & 43 & 84 \\
\hline & Empty & 14 & 20 & 25 & 41 & 66 \\
\hline \multirow[t]{2}{*}{ F94 } & Live & 0 & 1 & 49 & 41 & 90 \\
\hline & Empty & 0 & 0 & 0 & 0 & 0 \\
\hline \multirow[t]{2}{*}{ S95 } & Live & 0 & 98 & 1 & 1 & 2 \\
\hline & Empty & 0 & 24 & 73 & 3 & 76 \\
\hline \multirow[t]{2}{*}{ F95 } & Live & 0 & 2 & 14 & 84 & 98 \\
\hline & Empty & 0 & 6 & 53 & 41 & 94 \\
\hline
\end{tabular}


crabs and empty shells was also consistently positive, but weaker during F95. This may indicate the hermit crab's ability to track live gastropods and their inability to track (i.e. predict) empty shell availability.

Strong coincident spatial patterns existed between hermit crabs and live gastropods. In each season sampled, aggregations of hermit crabs with densities greater than the overall mean were closely associated with the highest live gastropod densities. This suggests that Pagurus maclaughlinae responds to the presence of gastropods as the ultimate provider of its shell resource (hermit crabs may also be tracking gastropods as a potential food source). The association between aggregations of hermit crabs and gastropods may be evolutionarily beneficial if the rate of decline in shell integrity upon the death of the gastropod inhabitant is rapid (LaBarbera \& Merz 1992). At least some aggregations of $P$. maclaughlinae also occurred where few or no empty shells were found. Interestingly, the mean number of hermit crabs and empty shells summed over all dates at the site closely matches that of live gastropods, suggesting that there may not be an abundant supply of potentially available resources for the hermit crab population. Restated, shell limitation may occur both before and after a shell becomes available for occupation by a hermit crab. Thus, we suggest that the relationships between this hermit crab and its resources are much more complex than can be deciphered from exclusive documentation of the availability of empty gastropod shells alone.

As was true for Pagurus maclaughlinae and its suite of gastropod shell resources, empty gastropod shells have been viewed as a rare commodity in hermit crab studies (e.g. Gherardi \& Vannini 1993). Thus, it may be beneficial for hermit crabs to actively aggregate not only at gastropod 'death sites' (sensu Gilchrist 1984), but also in areas of elevated live gastropod abundance even if those shells are not immediately available. This hypothesis is supported by the observation that hermit crabs collected from gastropod predation sites often have heavily fouled and/or damaged shells (Hazlett \& Herrnkind 1980, Gilchrist 1984, Gilchrist \& Abele 1984, Rittschof 1980a,b, Rittschof et al. 1992, Katz \& Rittschof 1993). Moreover, this suggests that hermit crabs with undesirable shells may respond more rapidly to death sites in an effort to increase their opportunity to obtain a desirable shell.

Diogenidae and Paguridae hermit crab aggregations have been previously reported (Snyder-Conn 1980, Gherardi \& Vannini 1989, 1992, 1993) but without the suggestion that these aggregations are in response to resources or resource providers, although hermit crab aggregations in response to chemical cues do occur (Gilchrist 1984). Thus, an alternative explanation for the observed distribution patterns in our study may be that Pagurus maclaughlinae formed clusters in responses to tidal flux and/or social behavior (sensu Gherardi \& Vannini 1992, 1993) in a similar manner to those formed by live gastropods in response to microhabitat differences (sensu Crowe 1996). Additionally, the clustering of hermit crabs has been postulated as advantageous in exploiting a food source (Kiester \& Slatkin 1974, Scully 1979, Gherardi 1990). Although not studied here, food availability (sensu Raimondi \& Lively 1986) may play a role in the distribution pattern displayed by $P$. maclaughlinae in Tampa Bay, especially if gastropods negatively influence the distribution of the epiphytic/epibenthic food sources through grazing activities. However, this influence was likely not important in the seagrass system studied here because of the opportunistic feeding behavior displayed by $P$. maclaughlinae (Robbins 1998).

Our results argue strongly for the inclusion of live gastropods as a measure, albeit temporally asynchronous, of resource availability for Pagurus maclaughlinae. Although in this study we found that hermit crabs and live gastropods were positively correlated, evidence in the literature also suggests that this relationship could be negative for other species. For example, the intertidal gastropod Nerita funiculata, a major provider of shells, had a negative effect on the distribution of the hermit crab Clibanarius digueti (Raimondi \& Lively 1986). Specifically, the experimental addition of $N$. funiculata resulted in a decrease in the density of $C$. digueti, which was interpreted as a response to a depressed common food source (Raimondi \& Lively 1986). Thus gastropods may play a role in the distribution of hermit crabs either through competitive interactions or as suppliers of an essential resource. Such dual roles of live gastropods, if common, would make it more difficult to discern resource patterns and elucidate their influence on patterns exhibited by the resource user.

In conclusion, we found that the link between the seagrass habitat's physical characteristics and Pagurus maclaughlinae and its shell resources was not strong. The association between $P$. maclaughlinae and its shell resources (both empty shells and live gastropods) was persistent and stronger than that to their common habitat, the seagrass Halodule wrightii. Aggregations of hermit crabs corresponded to areas of high live gastropod density across the landscape. Documentation of the dynamics of gastropod shell provision and their removal from the system over a landscape scale in future studies would aid in determining the patterns of hermit crab distributions compared to their shell resources.

Acknowledgements. We thank Drs. S. L. Jensen and R. A. Brooks, who participated in the collection of these data. Comments on this manuscript by Drs. M. Beck and B. Boese are greatly appreciated. This work, supported in part by grants 
from NSF (DEB 9318130), was completed in partial fulfillment of a PhD by B.D.R. from the Department of Biology, University of South Florida, Tampa, Florida.

\section{LITERATURE CITED}

Abrams PA (1980) Resource segregation and interspecific competition in a tropical hermit crab community. Oecologia (Berlin) 46:365-379

Attrill MJ, Strong JA, Rowden AA (2000) Are macroinvertebrate communities influenced by seagrass structural complexity? Ecography 23:114-121

Bell JD, Pollard, DA (1989) Ecology of fish assemblages and fisheries associated with seagrasses. In: Larkum AWD, McComb AJ, Shephard SA (eds) Biology of seagrasses. Elsevier, Amsterdam p 536-564

Bell JD, Steffe AS, Westoby M (1988) Location of seagrass beds in estuaries: effects on associated fish and decapods. J Exp Mar Biol Ecol 122:127-146

Connolly RM (1994) Removal of seagrass canopy: effects on small fish and their prey. J Exp Mar Biol Ecol 184:99-110

Crowe T (1996) Different effects of microhabitat fragmentation on patterns of dispersal of an intertidal gastropod in two habitats. J Exp Mar Biol Ecol 206:83-108

Danielson BJ (1991) Communities in a landscape: the influence of habitat heterogeneity on the interactions between species. Am Nat 138:1105-1120

Davis JC (1986) Statistics and data analysis in geology, 2nd edn. John Wiley \& Sons, New York

Gherardi F (1990) Competition and coexistence in two Mediterranean hermit crabs, Calcinus ornatus (Roux) and Clibanarius erythropus (Latreille) (Decapoda, Anomura). J Exp Mar Biol Ecol 143:221-238

Gherardi F, Vannini M (1989) Field observations on activity and clustering in two intertidal hermit crabs, Clibanarius virescens and Calcinus laevimanus (Decapoda, Anomura). Mar Behav Physiol 14:145-159

Gherardi F, Vannini M (1992) Hermit crabs in a mangrove swamp: clustering dynamics in Clibanarius laevimanus. Mar Behav Physiol 21:85-104

Gherardi F, Vannini M (1993) Hermit crabs in a mangrove swamp: proximate and ultimate factors in the clustering of Clibanarius laevimanus. J Exp Mar Biol Ecol 168:167-187

Gilchrist SL (1982) A critical view of hermit crab shell use. $\mathrm{PhD}$ thesis, Florida State University, Tallahassee, FL

Gilchrist SL (1984) Specificity of hermit crab attraction to gastropod predation sites. J Chem Ecol 10:569-582

Gilchrist SL, Abele LG (1984) Effects of sampling method on the estimation of population parameters in hermit crabs. J Crustac Biol 4:645-654

Hazlett BA (1970) Interspecific shell fighting in three sympatric species of hermit crabs in Hawaii. Pac Sci 24:472-482

Hazlett BA, Herrnkind WF (1980) Orientation to shell events by the hermit crab Clibanarius vittatus (Bosc) (Decapoda, Paguridae). Crustaceana 39:311-314

Heck KL Jr, Wetstone GS (1977) Habitat complexity and invertebrate species richness and abundance in tropical seagrass meadows. J Biogeogr 4:135-142

Hovel KA, Lipcius RN (2002) Effects of seagrass habitat fragmentation on juvenile blue crab survival and abundance. J Exp Mar Biol Ecol 271:75-98

Howell DC (1987) Statistical methods for psychology, 2nd edn. Duxbury Press, Boston, MA

Irlandi EA, Ambrose WG Jr, Orlando BA (1994) Landscape ecology and the marine environment: how seagrass landscapes influence growth and survival of juvenile bay scallops. Oikos 72:307-313

Editorial responsibility: Kenneth Heck (Contributing Editor), Dauphin Island, Alabama, USA
Katz JN, Rittschof D (1993) Alarm/investigation responses of hermit crabs as related to shell fit and crab size. Mar Behav Physiol 22:171-182

Kellogg CW (1976) Gastropod shells: a potentially limiting resource for hermit crabs. J Expl Mar Biol Ecol 22:101-111

Kiester AR, Slatkin M (1974) A strategy of movement and resource utilization. Theoret Popul Biol 6:1-20

Koerper G (1993) r.surf.idw - Surface interpolation utility for raster maps. In: GRASS 4.1 User's Reference Manual. US-Army Corp of Engineers. Champaign, IL

LaBarbera M, Merz RA (1992) Postmortem changes in strength of gastropod shells: evolutionary implications for hermit crabs, snails, and their mutual predators. Paleobiology 18: 367-377

Lancaster I, Wigham GD (1990) Influences on movement and migration in the hermit crab Pagurus bernhardus. J Mar Biol Assoc UK 70:483-491

McLean R (1983) Gastropod shells: a dynamic resource that helps shape benthic community structure. J Exp Mar Biol Ecol 69:151-174

Orth RJ, Heck KL Jr, van Montfrans J (1984) Faunal communities in seagrass beds: a review of the influence of plant structure and prey characteristics on predator-prey relationships. Estuaries 7:339-350

Provenzano AJ Jr (1960) Notes on Bermuda hermit crabs (Crustacea: Anomura). Bull Mar Sci Gulf Caribb 10:117-124

Raimondi PT, Lively CM (1986) Positive abundance and negative distribution effects of a gastropod on an intertidal hermit crab. Oecologia (Berlin) 69:213-216

Rittschof D (1980a) Chemical attraction of hermit crabs and other attendants to simulated gastropod predation sites. J Chem Ecol 6:103-118

Rittschof D (1980b) Enzymatic production of small molecules attracting hermit crabs to simulated gastropod predation sites. J Chem Ecol 6:665-675

Rittschof D, Tsai DW, Massey PG, Blanco L, Kueber GL Jr, Haas RJ Jr (1992) Chemical mediation of behavior in hermit crabs: alarm and aggregation cues. J Chem Ecol 18:959-984

Robbins BD (1998) The hermit crab Pagurus maclaughlinae, and live gastropods: an investigation on resource provision in a subtidal seagrass landscape. PhD thesis, University of South Florida, Tampa, FL

Robbins BD, Bell SS (2000) Dynamics of a subtidal seagrass landscape: seasonal and annual change in relation to water depth. Ecology 81:1193-1205

Scully EP (1979) The effects of gastropod shell availability and habitat characteristics on shell utilization by the intertidal hermit crab Pagurus longicarpus Say. J Exp Mar Biol Ecol 37:139-152

Spight TM (1977) Availability and use of shells by intertidal hermit crabs. Biol Bull (Woods Hole) 152:120-133

Snyder-Conn E (1980) The adaptive significance of clustering in the hermit crab Clibanarius digueti. Mar Behav Physiol 8: 43-53

Tunberg BG, Nelson WG, Smith G (1994) Population ecology of Pagurus maclaughlinae Garcia-Gomez (Decapoda: Anomura: Paguridae) in the Indian River Lagoon, Florida. J Crustac Biol 14(4):686-699

Walters WL, Griffiths CL (1987) Patterns of distribution, abundance, and shell utilization amongst hermit crabs, Diogenes brevirostris. S Afr J Zool 22:269-277

Worthington DG, Ferrell DJ, McNeill SE, Bell JD (1992) Effects of the shoot density of seagrass on fish and decapods: are correlation evident over larger spatial scales? Mar Biol 112: 139-146

Zar JH (1996) Biostatistical analysis, 3rd edn. Prentice Hall, Upper Saddle River, NJ

Submitted: August 25, 2003; Accepted: July 26, 2004

Proofs received from author(s): October 27, 2004 